\title{
Structure Analysis of Magnetic Multilayer Using Reflectometry
}

Tatsumi Hirano

Hitachi Research Lab., Hitachi Ltd.

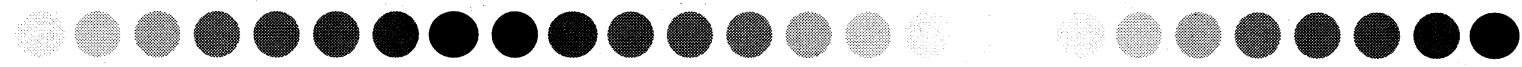

\begin{abstract}
The giant magnetoresistive head, consisting of magnetic and noble metal multilayers, is a key device of hard disk drives. As head properties strongly depend on the magnetic structure, the characterization is important for producing good devices. In this report, we review multi-wave x-ray reflectometry for accurate analysis of the layer thickness, and polarized neutron reflectometry for analysis of magnetic moment. We also mention a future prospect of a neutron experiment.
\end{abstract}

Keywords: Giant magnetoresistance, magnetic structure analysis, Reflectometry

1.はじめに

現在の磁気ディスク装置（HDD）の記録密度は 年率 $40 \%$ 程度で向上しており，記録密度が 400 $\mathrm{Gb} / \mathrm{in}^{2}$ の HDD が精力的に研究・開発されている. その開発は磁気ヘッドの高感度化と狭トラック化 が鍵である.GMR（Giant MagnetoResistance）へ ッドの基本構造は非磁性層（ $\mathrm{Cu}$ ) を, 固定層, 自 由層と呼ばれる 2 層の強磁性層 ( $\mathrm{NiFe}, \mathrm{CoFe}$ など) で挟んだ構造で, サブ $\mathrm{nm}$ から数 $\mathrm{nm}$ 膜厚の反強 磁性層／磁化固定層／非磁性層／磁化自由層の積 層構造からなる. その高感度化に向けて積層膜の 極薄膜化と固定層・自由層の多層化が検討されて いる。また，狭トラック化により，媒体からの磁 束を感じるへッドの体積も, 結晶数 10 個分にしか ならない。このため, 高度な磁化制御技術が必要 で, 各積層膜の膜厚だけでなく, 各磁性層の磁気 モーメントや界面における磁気構造の計測技術が 重要となっている. そこで, 積層磁性膜の各磁気 モーメントを分離して計測できる偏極中性子反射 率[1]に着目し，基本的な GMR ヘッド構造からな る積層磁性膜に適用した。本稿では, 多波長 X線 反射率法によるサブ $\mathrm{nm}$ の膜厚解析, 偏極中性子 反射率による磁気構造解析, 中性子実験への期待 について紹介する。

2. 多波長 $X$ 線反射率法によるサブ $\mathrm{nm}$ 膜厚解析

$\mathrm{X}$ 線反射率法は各積層膜の密度 (屈折率に比例), 膜厚, 界面凹凸を非破壊で評価する有力な手法で ある[2]. しかし, 遷移金属からなる GMR 膜構造 においては，その屈折率差が非常に小さいため, 界面で反射する $\mathrm{X}$ 線が少なく, 積層構造の解析が 困難であるという問題があった。 そこで，元素の 吸収端波長近傍では，屈折率が小さくなる異常分
散効果に着目し, $\mathrm{Co}-\mathrm{K} \beta$ 線や $\mathrm{Cu}-\mathrm{K} \beta$ 線の $\mathrm{X}$ 線波長 を用いることで GMR 膜の積層構造を解析できる ことを確認した[3-5]. 更に，複数波長で測定した 反射率を同時に解析する多波長 X線反射率法を開 発し, サブ nm の膜厚まで解析できることを示し た[6-8]. 以下では，その内容について紹介する.

\section{1. 実験方法}

GMR 膜の構造は, $\mathrm{Si}$ 基板 $/ \mathrm{Ta}(5) / \mathrm{NiFe}(5) / \mathrm{CoFe}(1) /$ $\mathrm{Cu}(2.3) / \mathrm{CoFe}(2) / \mathrm{Ru}(\mathrm{t}) / \mathrm{CoFe}(1.5) / \mathrm{CrMnPt}(20) / \mathrm{Ta}(3)$ である. 括弧内の数值は $\mathrm{nm}$ 単位の膜厚である. $\mathrm{Ru}$ の膜厚 $\mathrm{t}$ は， $0 \sim 0.8 \mathrm{~nm}$ とした．X 線反射率は $\mathrm{Co}-\mathrm{K} \beta, \mathrm{Cu}-\mathrm{K} \beta, \mathrm{Cu}-\mathrm{K} \alpha 1$ の波長で測定した。最小 二乗法により各波長の反射率を同時に解析し，各 層の屈折率, 膜厚, 界面凹凸を最適化した。

\section{2. 実験結果}

Fig. 1 に Ru 膜厚が $0.4 \mathrm{~nm}$ での, 測定反射率と最 適化後の計算反射率を示す．测定反射率と計算反 射率は非常に良く一致しており，高い精度で解析 できていることがわかる. Ru の解析膜厚と設計膜 厚との関係を Fig.2 に示す. 両者は，非常に良い 直線性を示しており，1）多波長X線反射率法によ りサブ nm までの膜厚が解析可能であること，2） 高度な成膜技術により, サブ $\mathrm{nm}$ まで膜厚制御が 可能であることがわかる.

これらの膜厚評価技術や成膜制御技術は, HDD の GMR ヘッドや記録媒体に活用されている.

\section{3. 偏極中性子反射率法による磁気構造解析}

$\mathrm{X}$ 線は電子雲との相互作用のため, $\mathrm{X}$ 線反射率 は電子密度の厚さ方向の構造変化（密度, 膜厚, 界面凹凸）に対応する。一方，スピン $1 / 2$ の中性 


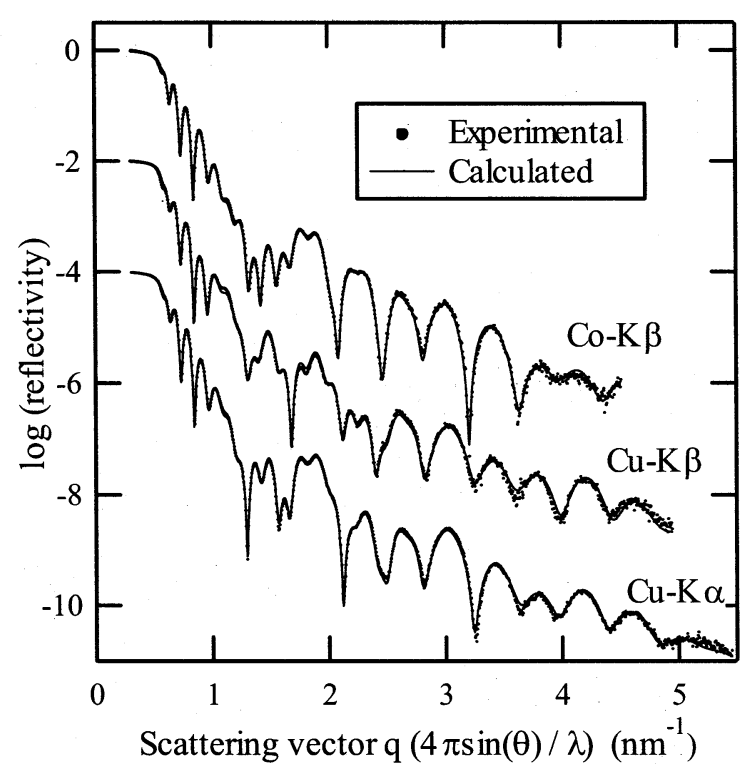

Fig.1 Experimental and calculated reflectivities measured at $\mathrm{Co}-\mathrm{K} \beta, \mathrm{Cu}-\mathrm{K} \beta$ and $\mathrm{Cu}-\mathrm{K} \alpha$ lines for the sample in the Ru thickness of $0.4 \mathrm{~nm}$.

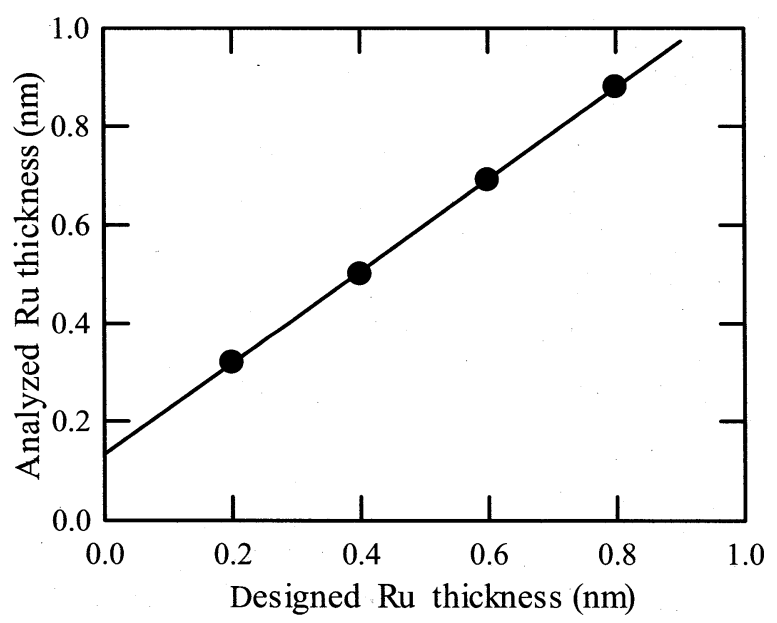

Fig.2 Designed Ru thickness dependence of analyzed Ru thickness.

子は原子核および磁気モーメントをもつ電子雲と の相互作用のため, 中性子反射率は, 原子核密度 および磁気モーメント密度の厚さ方向の構造変化 に対応する.積層磁性膜からの中性子反射率では, 各層の磁気モーメントや界面での磁気構造変化が 解析できる．更に，中性子のスピンの方向をそろ えた偏極中性子の反射率では, 微小な磁気モ一メ ントや磁気構造が検出できる利点がある. HDD の 高記録密度化に伴い, GMR ヘッドや記録媒体の 高度な磁化制御技術が必要で, 各磁性層の磁気モ 一メントや界面における磁気構造の評価が重要と なっている，以下では，その評価例について紹介 する[9].

\section{1. 実験方法}

測定試料は, GMR 構造の一部である以下の膜 構成である. ガラス基板/ $\mathrm{Ta}(1) / \mathrm{NiFe}(2) / \mathrm{PtMn}(12) /$ $\mathrm{CoFe}(2) / \mathrm{Cu}(2.5) / \mathrm{Ta}(1)$. 括弧内の数值は膜厚で $\mathrm{nm}$ 単位である. $\mathrm{CoFe}$ 層の着磁のため磁場中で熱処理

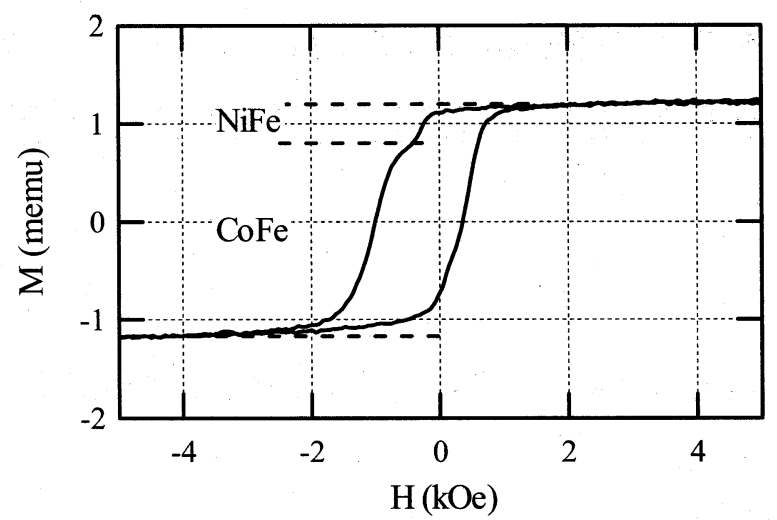

Fig.3 M-H loop measured by VSM.

した. 測定は, 高エネルギー加速器研究機構・中 性子科学研究施設に設置してある偏極中性子反射 率計（PORE）を用い, 外部磁場 $10 \mathrm{kOe}$ 下で計測 した. X 線反射率は $\mathrm{Cu}-\mathrm{K} \alpha 1$ の波長で測定した.

\section{2. 実験結果}

Fig.3 に振動試料型磁力計 (Vibrating Sample Magnetometer, VSM）の測定結果を示す. 着磁方 向は, 横軸 (外部磁場) の正方向に対応する. 外 部磁場が正から負になると, $\mathrm{NiFe}$ の磁化が先に反 転した後, $\mathrm{CoFe}$ の磁化が反転する．ヒステリシス の中央は原点ではなく, 負側にずれている.これ は，着磁した $\mathrm{CoFe}$ の磁化が反転しにくいからで ある (交換結合バイアネ)。これから， $\mathrm{NiFe}$ の磁 気モーメントは〜 $0.5 \mu_{\mathrm{B}}, \mathrm{CoFe}$ は $1.9 \mu_{\mathrm{B}}$ となる.

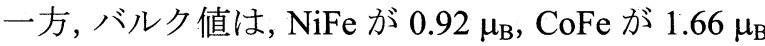
であり, $\mathrm{NiFe}$ の磁気モーメントが半減している.

Fig.4に中性子および X 線反射率の測定と最適 化後の計算反射率を併せて示寸，横軸は，両者の 反射率が比較できる散乱べクトル $q$ で表示した.

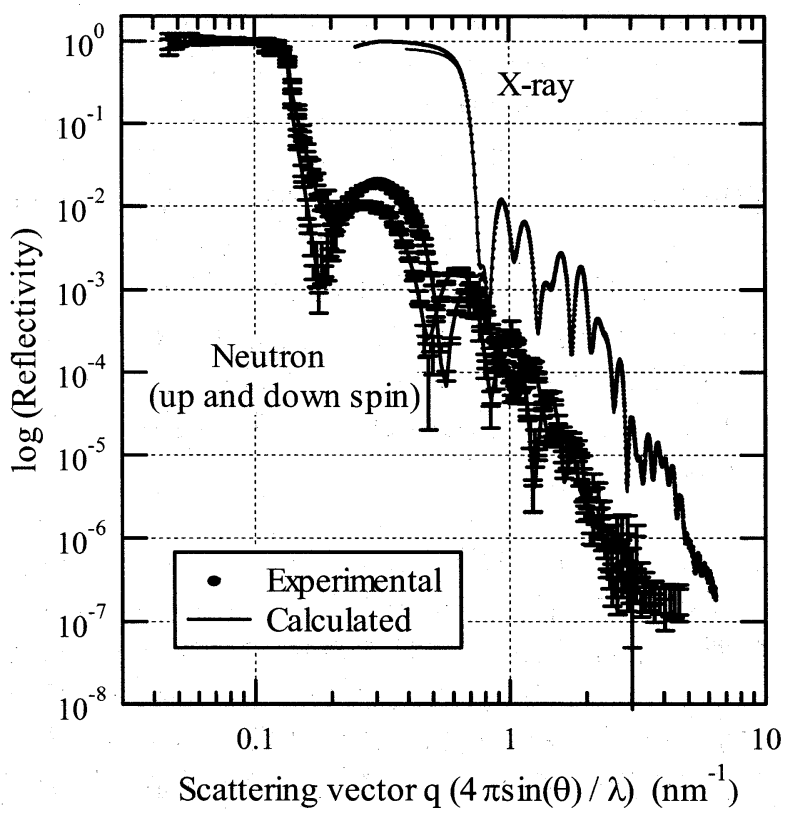

Fig.4 Experimental and calculated reflectivities of neutron and $\mathrm{x}$-ray . 
中性子の全反射領域は，X線のそれに比べて $1 / 5$ 程度小さい。これは，中性子とX線に対する物質 の屈折率の違いによる. 中性子反射率では, 膜厚 による振動の数がX線反射率に比べて少ないため, 膜厚の解析精度が低下すると予想される. そこで, X線反射率で膜厚を解析し, その結果を中性子反 射率の解析に反映させた.

膜構造モデルは，ガラス基板/界面層( $\mathrm{IF}) / \mathrm{Ta} /$ $\mathrm{NiFe} / \mathrm{PtMn} / \mathrm{CoFe} / \mathrm{Cu} / \mathrm{TaOx}$ とした。線部が成膜し た構成と異なる. 界面層は, ガラス最表面層と $\mathrm{Ta}$ とのミキシング層に対応する. 表面の Ta は $1 \mathrm{~nm}$ と薄いので，全て酸化していると考えられる．中 性子反射率では, ガラス基板と $\mathrm{Ta}$ 間の界面層は中 性子反射にはきかないので無視した。

$\mathrm{X}$ 線反射率の解析では，ガラス基板，下層 $\mathrm{Ta}$, $\mathrm{NiFe}, \mathrm{PtMn}, \mathrm{CoFe}, \mathrm{Cu}$ の密度は理論值に固定し て解析した. その結果の一部を Table 1 に示す.

$\mathrm{CoFe}, \mathrm{PtMn}$ の解析膜厚はほぼ設計值どおりであ る. 界面幅も $0.4 \sim 0.5 \mathrm{~nm}$ 程度で従来值である.

一方， $\mathrm{Ta} / \mathrm{NiFe}$ の界面幅は $0.8 \mathrm{~nm}$ と大きい。これ は， $\mathrm{Ta}$ と $\mathrm{NiFe}$ の反応層が形成されたためで, $\mathrm{Fe}$ に比べて Ni が Ta と反応しやすく, Ni 量が $\mathrm{Ta}$ 側 で若干多くなる現象で，従来より知られている現 象である[4]. この反応層の形成が, $\mathrm{NiFe}$ の磁気モ 一メントが半減する要因と考えられる.

中性子反射率の解析では，下層 $\mathrm{Ta}, \mathrm{NiFe}, \mathrm{CoFe}$ の核散乱長密度は理論值に，ガラス基板は実験值 に固定して解析した。 また, 下層 $\mathrm{Ta}$ と $\mathrm{CoFe}$ の膜 厚は, $\mathrm{X}$ 線反射率の結果に固定した。外部磁場 10kOe における $\mathrm{CoFe}$ と $\mathrm{NiFe}$ の磁気モーメントは 各々, $1.78 \mu_{\mathrm{B}}$ と $0.56 \mu_{\mathrm{B}}$ である.この值は, VSM の結果とほぼ一致している. CoFe の磁気モーメン 卜は理論值と $8 \%$ 以内で一致している. PtMn の中 性子反射率による膜厚は, $\mathrm{X}$ 線反射率に比べて $0.8 \mathrm{~nm}$ 大きい。 また, PtMn と $\mathrm{CoFe}$ 間の界面幅も $1 \mathrm{~nm}$ と X 線反射率の結果に比べて大きく, PtMn と $\mathrm{CoFe}$ の磁気的な結合は, 界面で広がっている ものと予想される。. また, $\mathrm{NiFe}$ と PtMn 間の界面 幅についても同様な傾向にある.

この反強磁性層の PtMn と磁化固定層 $\mathrm{CoFe}$ 間の 磁気構造の制御は, 高記録密度に対応した GMR ヘッドの開発において重要な課題となっている.

\section{4. 中性子実験への期待}

HDD の高記録密度化に伴い, 磁気ヘッドの素子 サイズは $100 \mathrm{~nm}$ 以下と縮小している.この素子加 エプロセスにより, 反強磁性層で本来固定される べき強磁性層の磁化が，回転および反転する現象 が顕在化し, 磁気ヘッド開発の課題となっている [10]. このため, 反強磁性層／強磁性層間の安定 した磁気結合の実現や，磁気構造の詳細な理解が 必要であり, 各研究機関で検討されている.

実用化された $\mathrm{L} 1_{0}$ 型の $\mathrm{PtMn} / \mathrm{CoFe}$ の交換結合工 ネルギーに比べ，4 倍高い $\mathrm{L}_{2}$ 型の $\mathrm{MnIr} / \mathrm{CoFe}$ が 開発[11]され，その実用化が期待されている。ま たその磁気構造は，フラストレーションモデルに
Table 1 Analytical results for neutron and x-ray reflectivities.

\begin{tabular}{|c|c|c|c|}
\hline 膜構造 & $\begin{array}{c}\text { 磁気モーメント } \\
\left(\mu_{\mathrm{B}}\right)\end{array}$ & $\begin{array}{l}\text { 膜厚 } \\
(\mathrm{nm})\end{array}$ & $\begin{array}{c}\text { 界面幅 } \\
(n m)\end{array}$ \\
\hline & 理論值:解析值 & X線：中性子 & X線：中性子 \\
\hline CoFe & 1.66 & 2.0 & 0.5 \\
\hline PtMn & 0 & 12.613 .4 & 0.5 \\
\hline $\mathrm{NiFe}$ & $0.92 \quad 0.56$ & $1.8: 1.6$ & 0.4 \\
\hline $\mathrm{Ta}$ & 0 & $1.3: \longleftarrow$ & $0.8: 0.8$ \\
\hline
\end{tabular}

よる理論的解勫 [12]も進められている. 一方, 磁 気構造評価は, 磁気円二色性による界面に固着し た $\mathrm{Mn}$ 磁化の存在[13]や, 円偏光 X線と偏極中性 子の反射率による界面近傍の磁化分布[14]が報告 されている. 特に, 後者の報告では, 中性子スピ ンに垂直な磁化成分により反射した中性子は，そ のスピンが反転する現象を利用しており, 界面磁 気構造の有力な評価技術と考えられる。 その実現 には，高強度な中性子線源が必要となる。

国内では，世界最高レベルの放射光施設 （SPring-8）が既に稼動しており, 同レベルの中 性子施設（J-PARC）の早期稼動が待たれている. HDD は国内の基幹産業の一つであり, 高性能材料 の開発, 理論解釈, $\mathrm{X}$ 線や中性子による構造評価 を相互に連携/活用することで, 世界市場を席巻 する産業にすることを期待したい.

\section{謝辞}

日本原子力研究開発機構, 高エネルギー加速器 研究機構, 日立グローバルストレージテクノロジ 一ズ，日立製作所の各機関の関係者に感謝いたし ます。

\section{参考文献}

[1] 武田全康, 日本応用磁気学会誌 26, 1025 (2002).

[2] T. C. Huang, J. -P. Nozieres, V. S. Speriosu, H. Lefakis and B. H. Gurney, Appl. Phys. Lett. 60, 1573 (1992).

[3] 宇佐美勝久他, 日本応用磁気学会誌 21,441 (1997).

[4] 平野辰巳他, 日本応用磁気学会誌 22, 190 (1998).

[5] T. Hirano, K. Usami, K. Ueda and H. Hoshiya, J. Synchrotron Rad. 5, 969 (1998).

[6] 宇佐美勝久他, 日本応用磁気学会誌 24,551 (2000).

[7] T. Hirano, K. Ueda and T. Imagawa, Trans. MRS-J 28, 35 (2003).

[8] S. A. Song, T. Hirano, J. B. Park, K. Kaji, K. H. Kim and S. Terada, Microsc. Microanal. 11, 431 (2005).

[9] 平野辰巳他, 日本応用磁気学会, 第 140 回研究 会資料, "層間磁気結合", 43 (2005).

[10] 西岡浩一他, 日本応用磁気学会, 第 140 回研 
究会資料, "層間磁気結合", 49 (2005).

[11] K. Imakita, M. Tsunoda and M. Takahashi, Appl. Phys. Lett. 85, 3812 (2004).

[12] C. Mitsumata, A. Sakuma and K. Fukamichi, IEEE Trans. Magn. 41, 2700 (2005).

[13] H. Ohldag et. al., Phys. Rev. Lett. 91, 017203 (2003).

[14] S. Roy et. al., Phys. Rev. Lett. 95, 047201 (2005). 